\title{
The Methodology of the Determination of Accumulated Damage Level and Achievement of the Limit State in Ferromagnetic Steel Structures
}

\author{
Kuzeev I.R. \\ Department of technological machines and equipment \\ Ufa State Petroleum Technical University \\ Ufa, Russia \\ kuzeev2002@mail.ru
}

Schipachev A.M.

Department of transportation and storage of oil and gas

Saint Petersburg Mining University

Saint Petersburg, Russia

schipachev_am@pers.spmi.ru

\author{
Naumkin E.A. \\ Department of technological machines and equipment \\ Ufa State Petroleum Technical University \\ Ufa, Russia \\ ynaumkin@mail.ru
}

\section{Gafarova V.A.}

Department of technological machines and equipment Ufa State Petroleum Technical University Ufa, Russia gafarova.vika@bk.ru

\author{
Sandakov V.A. \\ The head of \\ Engineering center «Technics» \\ Ufa, Russia \\ gafarova.vika@bk.ru
}

\begin{abstract}
The insurance of the safety of extended facilities, such as pipeline systems, raises the issue of continuous monitoring of their technical condition and control of accumulated damage. A similar problem arises in the operation of hazardous facilities with a large surface area, which include oil and gas technology reactors, reservoirs. The complexity of the problem lies in the large uncertainty of the state of the system, the initial conditions of which are not always known. At the same time, such objects are distinguished by a non-uniform distribution of mechanical properties and a non-uniform stressed-deformed state.

It is shown that the traditional ways of ensuring the security of complex systems exhaust their resources, because the destruction occurs despite the improvement of diagnostic tools. The authors, formulating a new approach to assessing the degree of resource exhaustion, proceed from the fact that it is necessary to distinguish the resource of a structural material and the resource of a structure, while the structural material when introducing energy from the outside tends to include various mechanisms of adaptation to external influences. The level of accumulated damage in metal structures is determined by monitoring changes in the electrical and magnetic characteristics of metal during cyclic loading. The dependence of the change in electrical and magnetic characteristics on the number of loading cycles has an extremum, which determines the limiting state of the metal.
\end{abstract}

Keywords - damage, electrical and magnetic characteristics, cyclic loads, limiting state, destruction

\section{INTRODUCTION}

Oil and gas technology involves the transportation of hydrocarbons over long distances. The main type of transport is pipeline transport. For example, the total length of trunk pipelines controlled only by "Transneft" is more than 70 thousand kilometers [1]. According to the authors of the work [1], the total length of pipelines for various purposes in Russia exceeds 500 thousand $\mathrm{km}$.

Ensuring the safety of such extended objects is a complex task that can be solved only by a complex method.

Constantly changing operating conditions and material aging require the implementation of multi-level pipeline control using stressed - deformed state modeling tools, in-line inspection, and corrosion control systems. It is important that the working pressure should not exceed the maximum allowable values.

Much attention is paid to in-line inspection based on the use of autonomous tools for various purposes. The profilers determine the geometry defects, and the projectiles equipped with ultrasonic and magnetic defectoscopes search for corrosion defects, the delamination of metal pipes, cracks and crack-like defects. The methods of in-line inspection are constantly being improved, but they have a number of drawbacks that are associated with the need to supply the pipeline under study with special traps for launching and 
receiving tools, the medium for the passage of sound waves, and magnetization of pipeline metal.

As it is shown by the experiments on the distribution of ultrasonic waves in a metal with different levels of accumulated damage and different pressures in the shell, the speed of passage of waves varies [2, 3]. Preliminary magnetization of pipes for the search of defects can create significant difficulties in carrying out repair work with the use of welding, which may require demagnetization. The magnetization of pipe steel deteriorates the quality of the repair weld, so demagnetization is considered a necessary technological operation [4].

Despite the constant attention paid to ensuring the safety of pipeline transport the accidents occur. For example, according to the data [4], 153 accidents of different complexity were recorded on gas pipelines in the period from 2005 to 2015. This fact indicates the need to find other solutions and principles for the assessment of the actual technical condition of pipelines.

\section{PROBLEM STATEMENT}

The starting point for research is the fact that the properties of metal change in the process of long loading. In order to answer the question about the exhaustion of the resource of a structure, it is necessary to realize that it is necessary to distinguish the resource of a material between the resources of a structure. Structural material when introducing energy in any form from outside, aspires to expend this energy. The aspiration of the system to minimize energy forces the structural material to include various mechanisms of adaptation to external conditions. The basis of these mechanisms is a simple scheme of polycrystalline material, which is shown in Figure 1. The structure consists of an ordered and chaotic part. The ordered part is determined by the translation of Bravais elementary lattices [5] (Figure 1, a).

The chaotic part is defined by the Franck's dislocation lattice (Figure 1, c). As a result of conjugation, a real structure arises (Figure 1, c). Such a simplified scheme allows presenting the basic properties of a polycrystalline material.

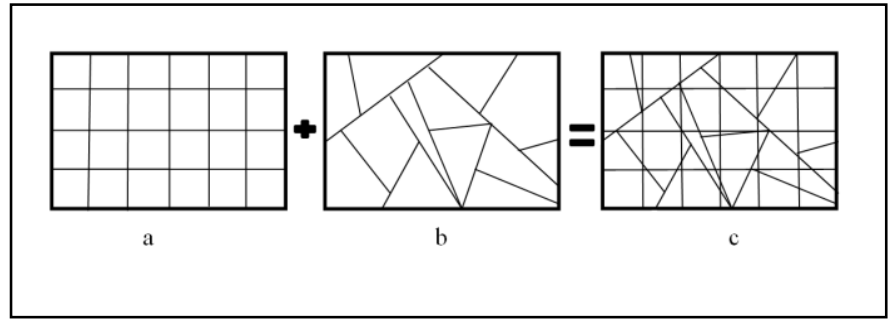

Fig. 1. A simplified scheme of a polycrystalline material: a - the ordered part, $\mathrm{b}$ - the Frank dislocation lattice, $\mathrm{c}$ - the conjugation of two components.

All the changes that occur in a polycrystalline material during external influence are related to the chaos / order ratio:

$\mathrm{Z}=$ chaos / order $=$ dislocation density / packing density of atoms.
An expert assessment gives a change in $\mathrm{Z}$ in real polycrystalline materials within $0.25-0.75$ and the upper limit means the realization of the destruction process. The study of various scenarios for the transition to chaos [6] indicates that there is a deep internal connection between order and chaos: a non-periodic random process is obtained as the limit of birth of periodic structures.

In open systems, the pumping of energy from the outside leads, in accordance with the second law of thermodynamics, to the increase in entropy, as a result the system tends to a chaotic state. However, in accordance with the theory of I. Prigogine about the emergence and development of dissipative structures [7], the system thus goes into the state with the least entropy production. The transitions are carried out by the bifurcation mechanism at the moment when the system reaches the maximum non-equilibrium state. The system responds to an increase in energy by a spontaneous transition to a more ordered state. However, the general trend in changing the properties of a structural material is presented by material exhaustion of its resource in order to ensure strength.

Polycrystalline material has a number of adaptation mechanisms to external influences that allow dissipation of the input energy at different scale levels. These mechanisms can be divided into volumetric and surface. Volumetric mechanisms are associated with various processes connected with changes in the grain structure (substructure), with phase transitions and the formation of new phases. Surface mechanisms are associated with corrosion of material, changes in surface energy, etc.

The following question arises: will the constructional material that is not used to create the structure, but is in a free state, for example, on the surface of the earth, exhaust its resources? From our point of view, it is necessary to give a positive answer. Being on the surface of the earth, a polycrystalline material undergoes environmental exposure when changing the atmospheric pressure, temperature, humidity, and the magnetic field of the Earth. The material in this case cannot respond to these changes. Everything depend on time.

In the limit, the structural material exhausts its durability, as it is shown in Figure 2.
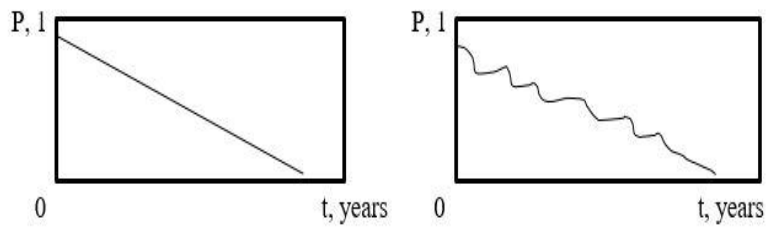

Fig. 2. The diagram of the loss of the durability of a structural material over time: a-idealized representations, $\mathrm{b}$ - the representations taking into account the mechanisms of adaptation to external loads, where $\mathrm{P}$ - the durability resource

The diagram does not start with a unit (1), since a full resource can be realized only in ideal crystals. Polycrystallinity itself already has low resource strength, 
associated, for example, with the presence of the Frank dislocation lattice. Unfortunately, a direct experiment is associated with the need to observe the material for hundreds of years. Therefore, the authors performed an experiment accelerating the reaction of a structural material to an external effect.

Figure 3 shows a device for bending steel plates in the elastic and elastic-plastic deformation areas.

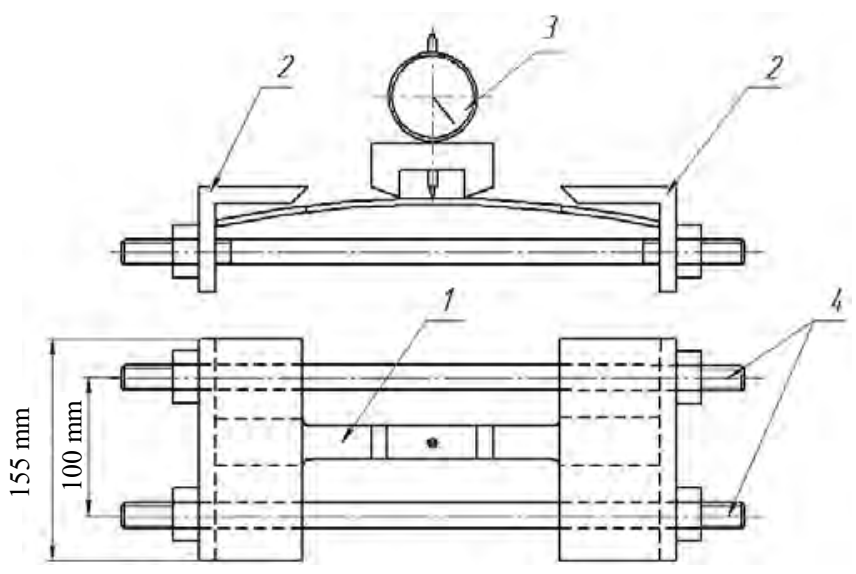

After the creation of a certain level of deformation, the samples remained in one position for a long time up to one year. Periodically, the samples were measured for the speed of longitudinal ultrasonic waves, as well as the tangential and normal components of the vector of a constant magnetic field. Figure 4 reflects the measurement results, which clearly show that, despite the stationarity of the load, the measured parameters are constantly changing. Due attention is drawn to the peak values of the measured parameters in the first 10-20 days of the experiment. One of the adaptation mechanisms starts to work. There is certain cyclicity in the change of parameters for the entire observation period.

Fig. 3. A device for static bending of flat samples and a device for measuring the deflection [8]: 1 - a flat sample; 2 - metal corners; 3 - device with a dial indicator; 4 - pins with fixing elements
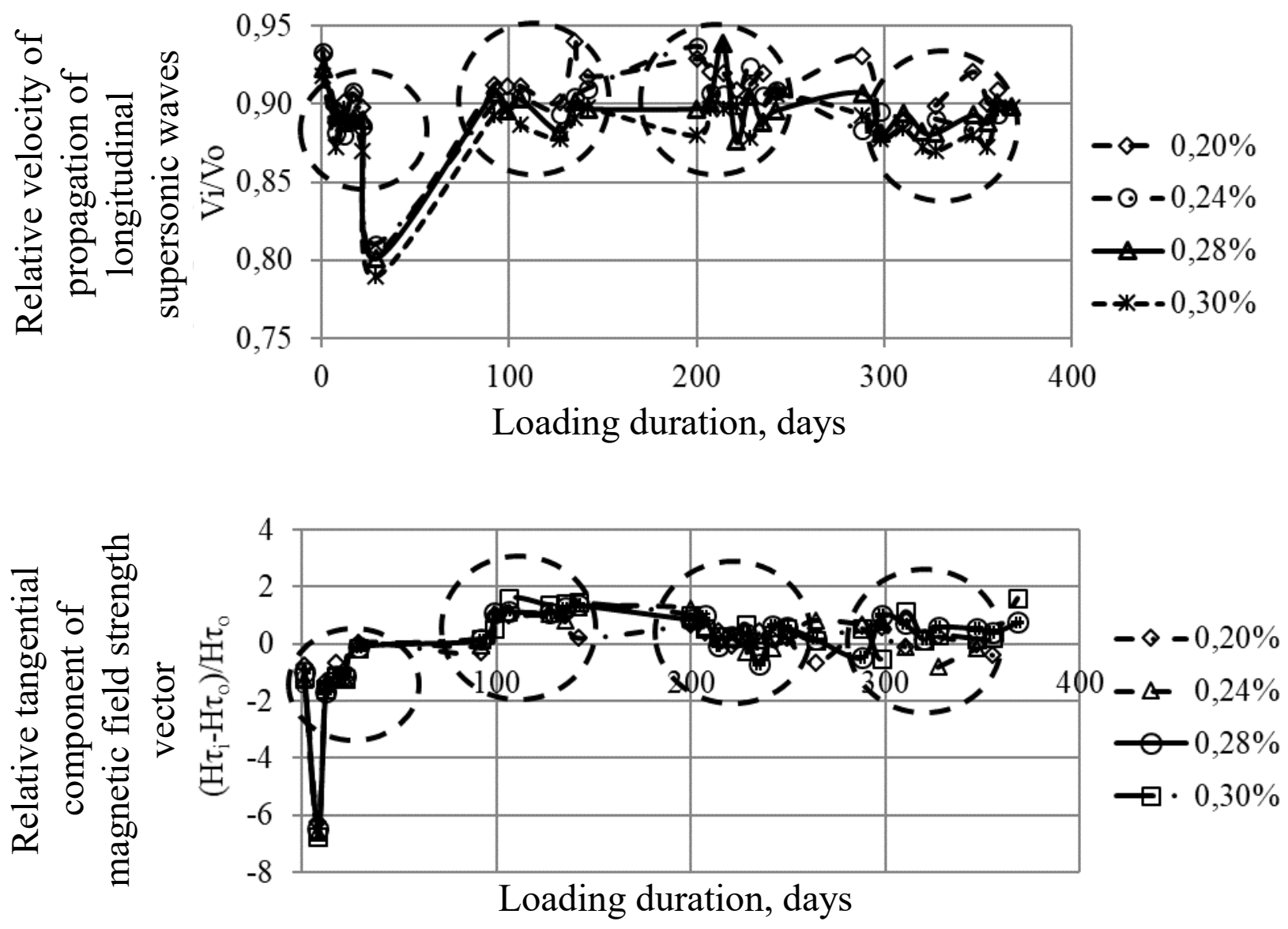


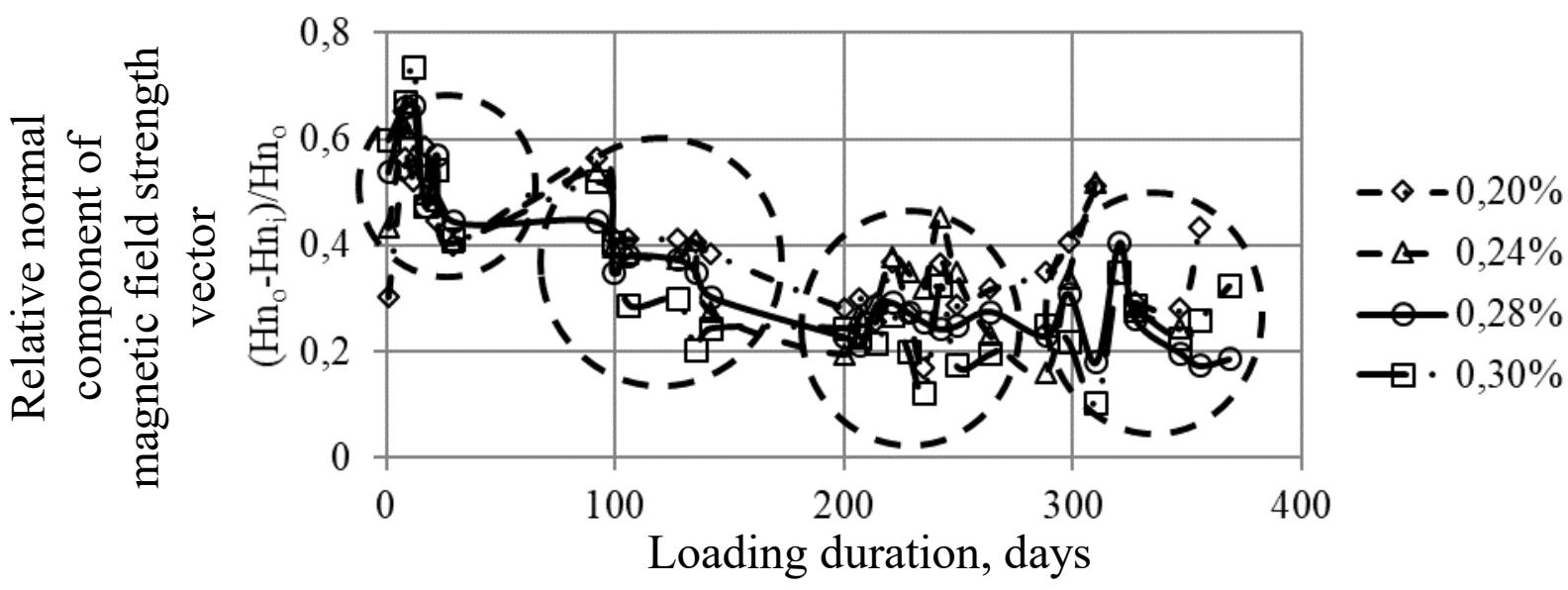

Fig. 4. The change in the velocity of longitudinal ultrasonic waves (a), tangential component (b) and normal component (c) of the vector of constant magnetic field strength from the loading duration at various levels of deformation [8]

These research results allow drawing the conclusion that the structural material evolves in the direction of exhaustion of strength properties. However, some physical parameters allow monitoring this process. Our task is to determine the most informative physical parameters that indicate the exhaustion of the resources of material and the onset of the ultimate state of pre-destruction.

\section{EXPERIMENTAL RESEARCH}

The experiments were performed on steel samples in various modes of cyclic variation of loading parameters. Obviously, cyclic loads can significantly reduce the test time, as it is shown in Figure 5.

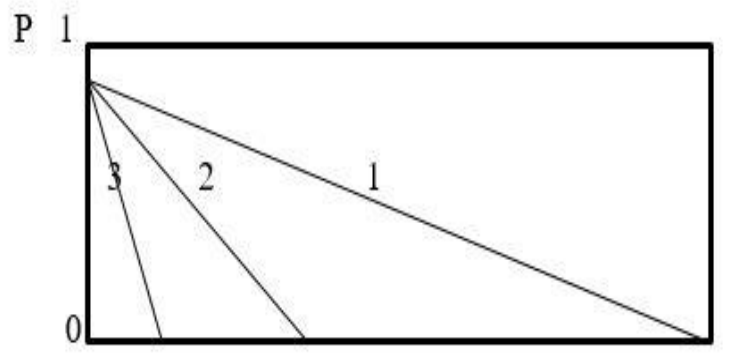

t, years

Fig. 5. The diagram of the loss of the resource strength of a structural material: 1 - when exposed to natural conditions; 2 - in the process of its static loading; 3 -in the process of its cyclic loading

Before we determine the most informative parameter for the assessment of the resource of material, it is necessary to discuss two fundamental points for our research.

The first point is related to the fact that no matter how many mechanisms of adaptation to external influences exist in the polycrystalline material, in the end it all comes down to the formation of a new surface. We perceive this new surface as a crack.
The experiments show that the evolution of the structure occurs in a series of formation: vacancies - micro-pores meso-pores - macro-pores - cracks. The evolution of the pore space of a polycrystalline material has fundamental basis. The modern theory of metallic bonding is based on the idea of an "electron gas" [5].

The valence electrons of metal atoms are collectivized and participate in creating an orderly structure, balancing the repulsive forces between positively charged ions. Since it is believed that the electron gas fills the space not occupied by lattice ions, all the voids are negatively charged.

As it is indicated in the work [9], the maximum mechanical stress corresponds to the minimum value of the electron energy and, as a result of the deformation; a potential well arises for a substance with a negative charge. Therefore, vacancies and micropores begin to shift to zones with maximum mechanical stresses. The confluence of vacancies and micropores eventually leads to the formation of microcracks and stress relaxation. When implementing such a mechanism, the electrical and magnetic characteristics of the polycrystalline material should change. Further experiments are based on this thesis.

The second moment is connected with the surface of the polycrystalline material, since measurements are carried out precisely from the surface. The analysis of various ideas about the nature of surface energy indicates an unresolved problem and allows other explanations. In the work [10], the author considers the properties of thin films and notes that one and the same film can be two- and three-dimensional, or it can have an intermediate dimension. The idea of a fractionally sized surface layer of a solid is formulated as follows: as the dimension of filling with three-dimensional space is reduced, when energy is transferred from a bulk part of a solid to its surface, it is experimentally detected as the surface energy of the condensed phase. Such a layer can be considered as a multifractal, if we take into account that all physical properties will specifically change when going from volume to surface.

It is also necessary to take into account that in the volume of a polycrystalline material there are also surface elements that are identified as grain boundaries, subgrains. In 
conjunction with the surface fractionally sized layer the boundaries of grains and subgrains form a macroscopic analogue of the Frank lattice. This analogy explains the fact that changes in the grain boundaries will inevitably be reflected in the surface layer and vice versa.
The experiments on the determination of surface energy were carried out in the process of fatigue testing of flat steel samples using the sitting drop method. Figure 6 shows the change in the wetting angle during the accumulation of fatigue damage.
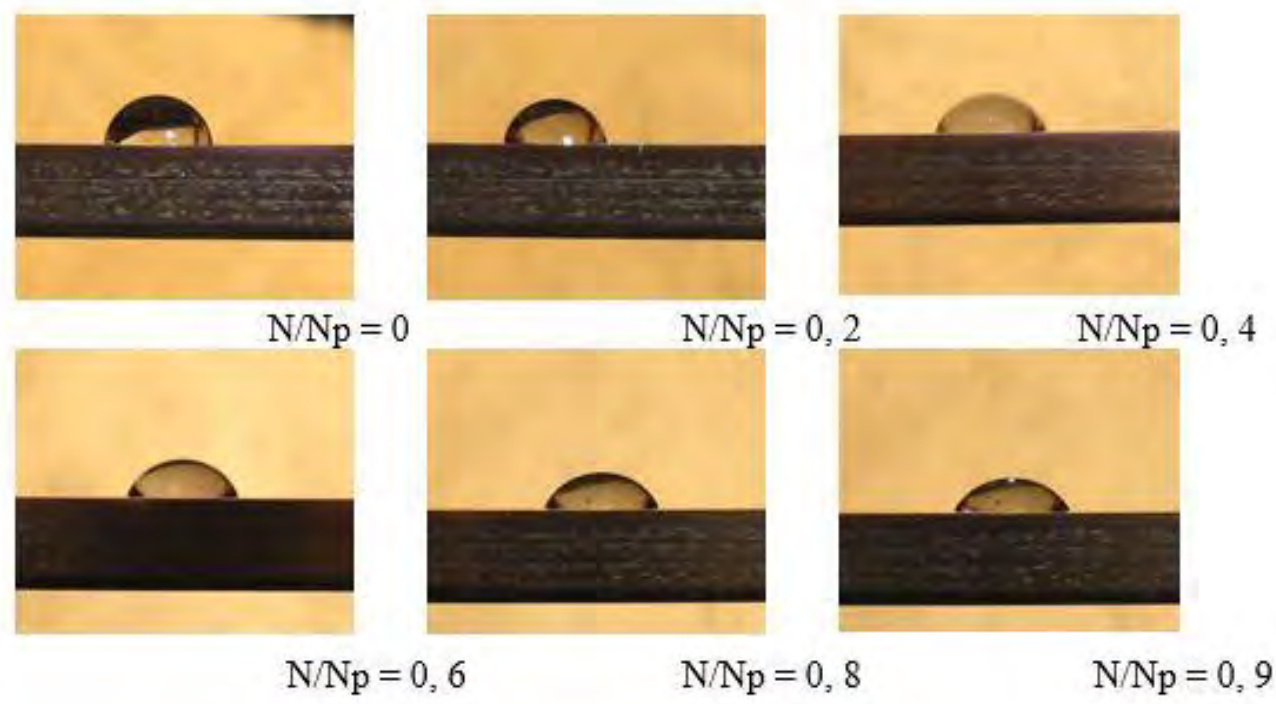

Fig. 6. The change in the wetting angle of the surface of steel 09G2S with increasing level of accumulation of fatigue damage

Using the above-mentioned method, the dependences of the surface energy of steels on the level of fatigue damage accumulation are created; they are shown in Figure 7, it reflects the increase in energy. It is necessary to pay attention to the fact that, with the same surface treatment of the tested samples, the surface energy for austenitic steel is significantly higher than for ferritic-pearlite steel. When $\mathrm{Ni} / \mathrm{Np}=0.3$ is reached, the growth of surface energy becomes unstable and there are no visible surface changes associated with the formation of microcracks. This is obviously is reasoned by the changes in the grain structure of the polycrystalline material.

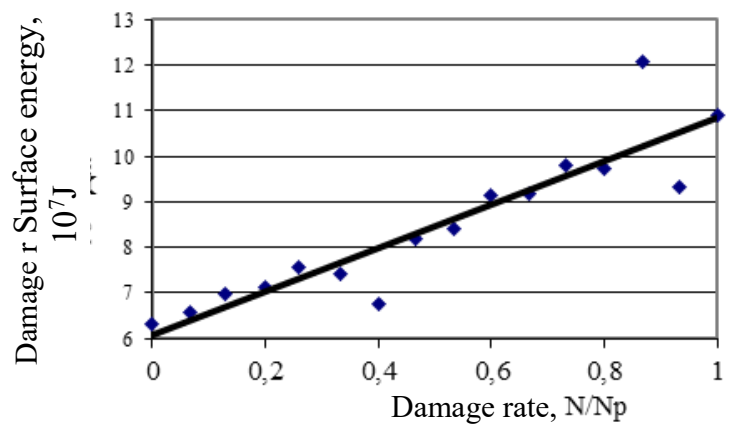

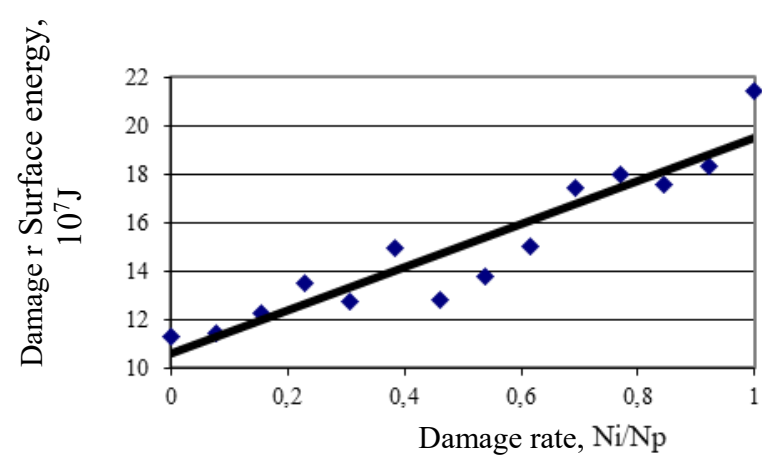

Fig. 7. The dependence of the surface energy of steel 09G2S (a) and $12 \mathrm{X} 18 \mathrm{H} 10 \mathrm{~T}$ (b) on the level of accumulation of fatigue damage, $\mathrm{Ni} / \mathrm{Np}$ - the ratio of the current value of the number of loading cycles $\mathrm{Ni}$ to the number of cycles at which Np samples are destroyed

Further studies are aimed at determining the possibility of the assessment of the place of future destruction in the early stages of deformation of metal samples. The experiments were carried out on flat samples, which were tested for the effect of cyclic loads in a low-cycle place according to the scheme of pure bending. 


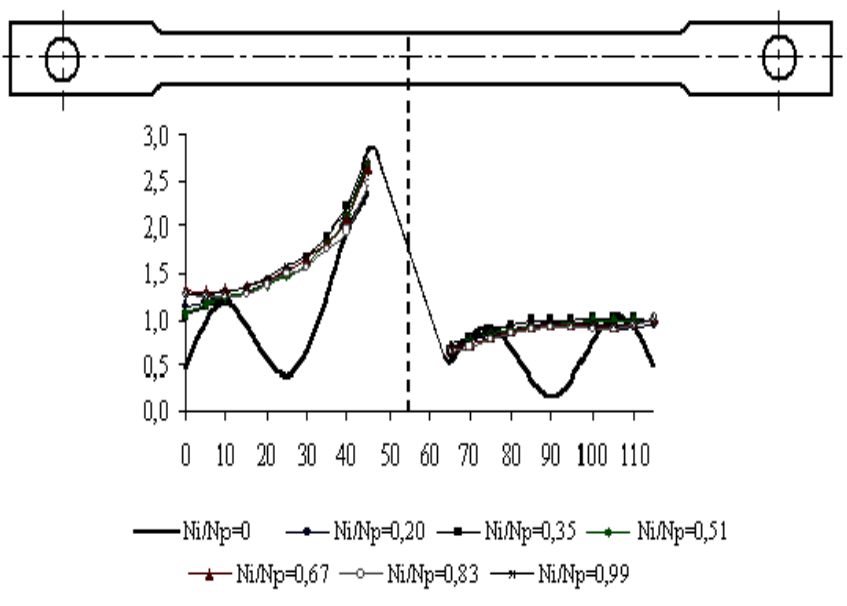

Fig. 8. The dependence of the change degree of the magnetic field strength along the length of the working zone of the sample with the accumulation of fatigue damage

Preliminary measurements of the magnetic field strength along the sample showed the presence of several zones with extreme values of tension (Figure 8). In the process of the deformation of the sample, all the extremes except one smoothed out. In the zone of the remaining extremum a crack was formed. These experiments indicate the potential for early diagnosis of the site of destruction. Hardness measurements along the sample showed the presence of a zone with reduced hardness, which corresponds to the area of destruction. The fracture has a cellular structure characteristic of the accumulation of pores (Figure 9).

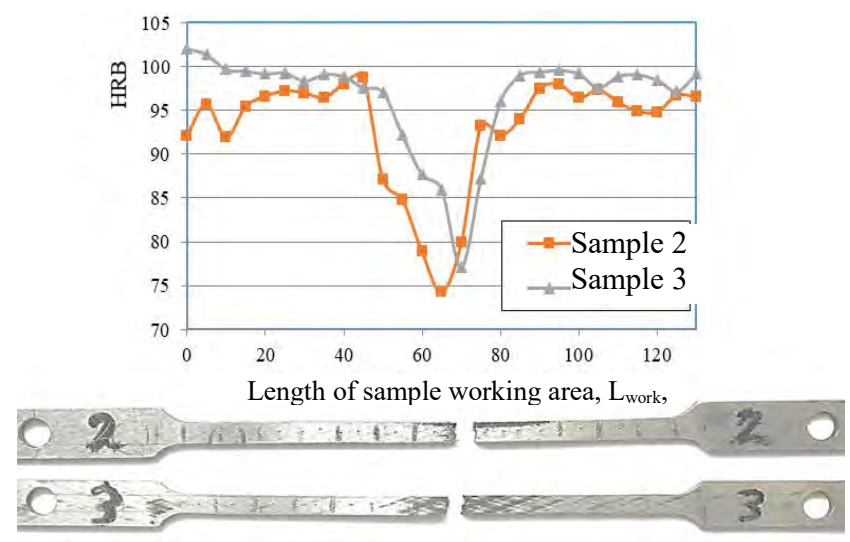

Fig. 9. The distribution of hardness along the length of the working zone of the sample after fatigue failure [11]

The next stage of research was connected with the determination of the most informative parameter of the response of an electrical signal, indicating the onset of a limit state in the process of cyclic loading. These tests were carried out in the framework of studying the characteristics of the destruction of steel GT-90, from which flexible tubing pipes were made. Preliminary studies showed that the following electrical signal parameters were the most informative [11, 12]:

- Average voltage response of an electrical signal

$$
\mathrm{U}_{\mathrm{av}}=\frac{1}{\mathrm{~T}} \int_{0}^{\mathrm{T}} \mathrm{u}(\mathrm{t}) \mathrm{dt}
$$

- Actual voltage of electrical response

$$
\mathrm{U}=\sqrt{\frac{1}{\mathrm{~T}} \int_{0}^{\mathrm{T}} \mathrm{u}^{2}(\mathrm{t}) \mathrm{dt}}
$$

- The coefficient of attenuation of the 3rd amplitude harmonic of damped oscillations of the response of an electrical signal

$$
\mathrm{K}_{3}=1-\frac{\mathrm{U}_{3}}{\mathrm{U}_{\max }}
$$

where U3 - the 3rd amplitude harmonic of the damped oscillations of the response of the electrical signal, Umax - the maximum voltage of the response of the electrical signal

- The coefficient of amplitude of the effective voltage response of electrical signal

$$
\mathrm{K}=\frac{\mathrm{U}}{\mathrm{U}_{\max }}
$$

Flat samples were tested. They were subjected to cyclic loading with simultaneous measurement of the parameters of the response of electrical signal every 500 cycles up to complete destruction.

According to the measurement results, the relative values of the average voltage $\mathrm{Ui} / \mathrm{Ui}-1$ were found for various relative amounts of $\mathrm{Ni} / \mathrm{Ni}-1$ cycles (where $\mathrm{Ni}$ is the number of cycles at the time of the current measurement, $\mathrm{Ni}-1$ is the number of cycles at the time of the previous measurement) and the distribution graphs are made of the measured parameter distribution along the working length of the sample. A characteristic relation is shown in Figure 10. A wellrepeated extremum is observed when reaching $80 \%$ of the number of cycles at which the destruction occurs.

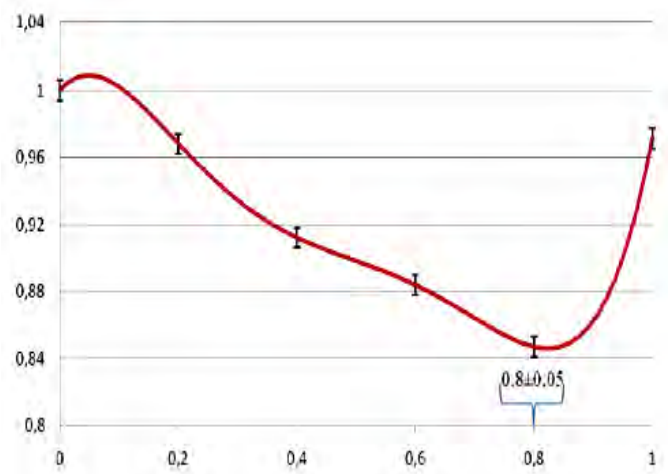

Fig. 10. The change in the relative average voltage response of the electrical signal from the level of accumulated fatigue damage in the zone of destruction [11] 
After the performance of the studies on flat samples, the shell structures (with a diameter of $89 \mathrm{~mm}$ and a wall thickness of $3 \mathrm{~mm}$ ) with elliptical bottoms and fittings for the supplement and the discharge of the working medium from steel 20 were made. The tests were carried out on an experimental test bench, where shell structures were subjected to cyclic loading with internal pressure in a low-cycle region until they were destroyed by a pulsating loading circuit with a value of the asymmetry coefficient of the cycle $\mathrm{R}=0$.

The pressure amplitude was chosen in order to provide the elastoplastic deformation of the material at stresses $(0.9 \div 1.1)$ $\sigma \mathrm{t}$. The yield strength was determined by the results of uniaxial stretching of standard flat samples according to allUnion State Standard 1497-84, which were made of a cylindrical shell material, and amounted to $361 \mathrm{MPa}$. Working pressure was calculated by the following formula [13]:

$$
\mathrm{p}=\frac{2 \cdot \varphi \cdot \mathrm{s}}{\mathrm{D}+\mathrm{s}} \cdot 0,9 \cdot \sigma_{\mathrm{T}}
$$

where

$\mathrm{s}$ - the wall thickness of the cylindrical shell, mm;

$\varphi$ - the coefficient of strength of the weld;

$\mathrm{D}$ - the inner diameter of the cylindrical shell, $\mathrm{mm}$;

$\sigma_{\mathrm{T}}$-yield strength of steel 20, MPa.

The maximum pressure of the experiment was $22.6 \mathrm{MPa}$, which corresponds to the maximum voltage of $325 \mathrm{MPa}$.

Figure 11 shows the shell structure before and after the deformation.
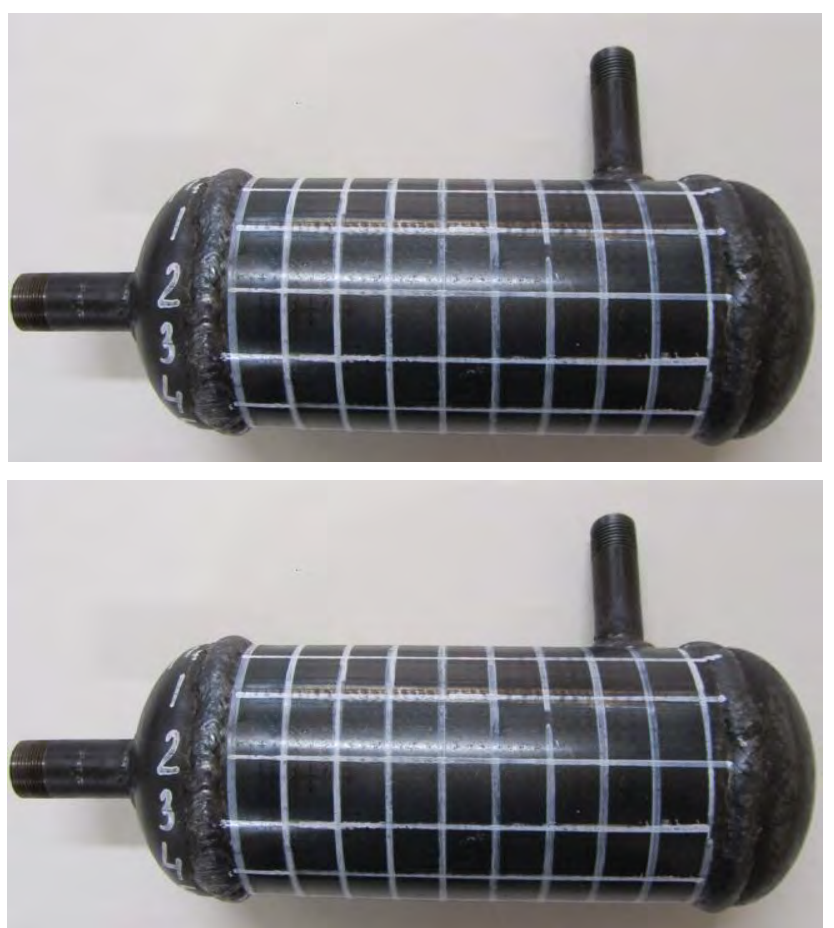

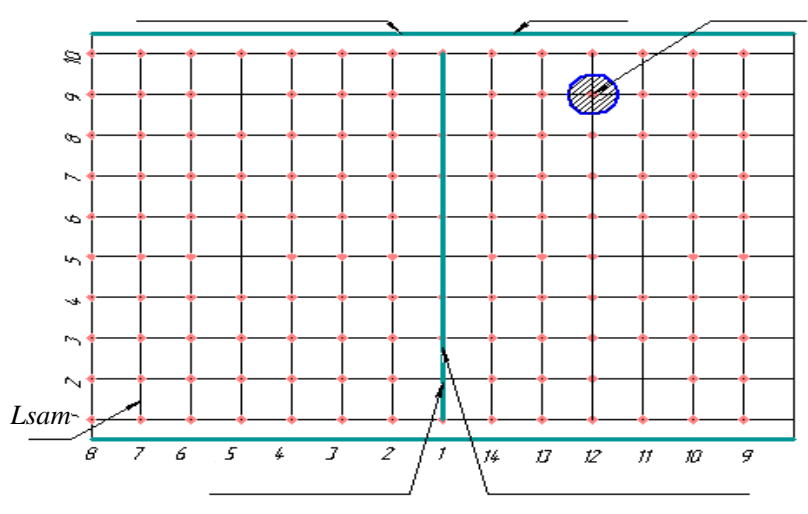

Fig. 11. Shell construction at the initial state (a) and after the destruction (b), scan with indication of the measurement zones of electromagnetic and mechanical characteristics (c) [12]

The destruction of shell structures occurred in the zone of the electrofusion joint (forming cylindrical shell No. 1) in the form of a crack. The analysis of the change in the average voltage of electrical signal response (Usr.i / Usr.out.) on a cylindrical shell from the level of accumulated fatigue damage directly in the zone of destruction and at some distance from it (Figure 12).

The dependence of the response of an electrical signal measured in the zone of destruction (Figure 12, a) corresponds to the dependence obtained on flat samples (Figure 10).

The measurements in areas greater than $20 \mathrm{~mm}$ from the point of occurrence of a crack of the changes in the electrical signal are not informative from the point of view of destruction diagnostics. At the same time, the results of the experiment correspond with the concept of the movement of a negative charge to the zone with a mechanical stress concentrator - a weld.

The obtained results indicate the need for a more detailed study of the formation of the response of electrical signal, as well as the possibility of two-parameter control. As a second parameter, it is possible to use the results of durometry. In connection with these, the measurement of hardness was made simultaneously with the measurements of the electrical signal.

The hardness index is an integral parameter that characterizes the mechanical properties of a polycrystalline material. The nature of changes in mechanical properties in local areas and over the entire surface of the shell as a whole can indicate the state of metal and the level of accumulated damage.

The inclusion of the concept of multifractals, based on the general concept of measure, is one of the most promising areas for the development of a systems approach in materials science [14]. This method allows quantifying the configuration of the distribution of any physical parameter as a whole, which cannot be achieved by other methods [15]. 

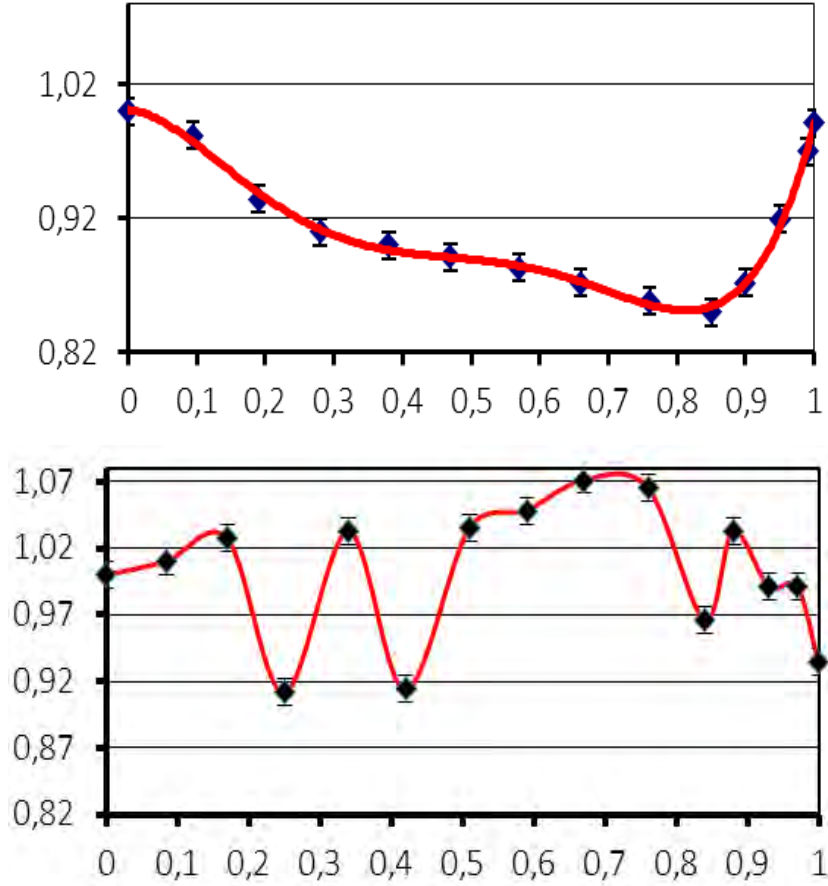

Fig. 12. The change in the average voltage of the response of electrical signal from the level of accumulated fatigue damage in the zone of destruction (a) and at a distance of more than $20 \mathrm{~mm}$ from the zone of destruction (b) with the number of loading cycles $2.3 \times 104$

Processing the results of the hardness measurement was carried out using the multifractal parameterization method using the software MFRDrom, developed by Professor G.V. Vstovsky [14].

The fractal dimension (D0), hidden order (D1-D40) and the degree of homogeneity (F40) $[13,16,17]$ are taken as multifractal parameters for the analysis. The results of the analysis are shown in Figure 13 as dependencies of multifractal parameters on the level of accumulated damage, which indicate the presence of extreme values of all calculated parameters when the value of the parameter is $\mathrm{Ni} / \mathrm{Np}=0.8 \pm$ 0.05 is reached.

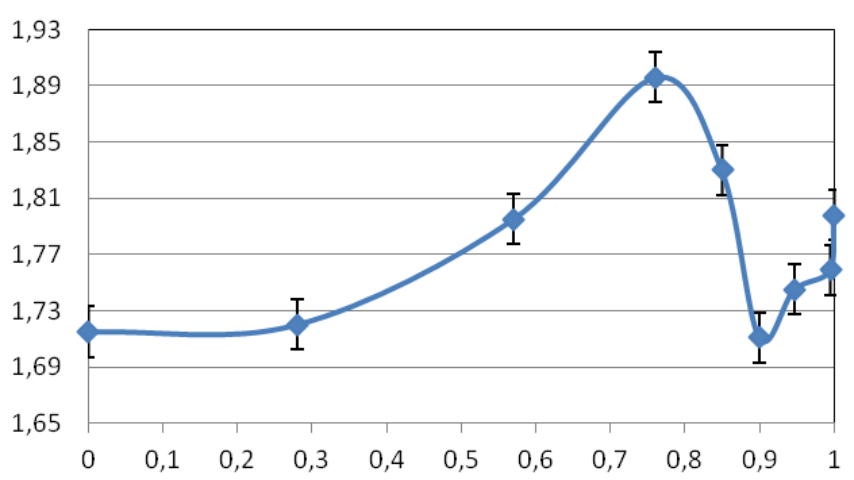

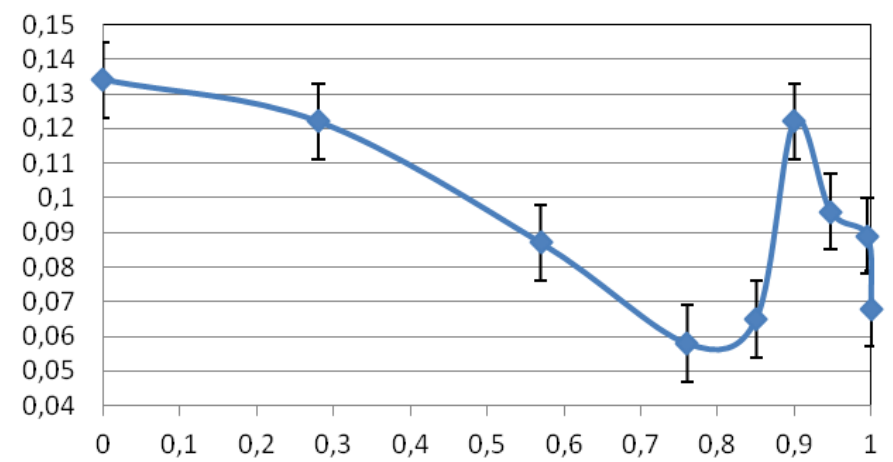

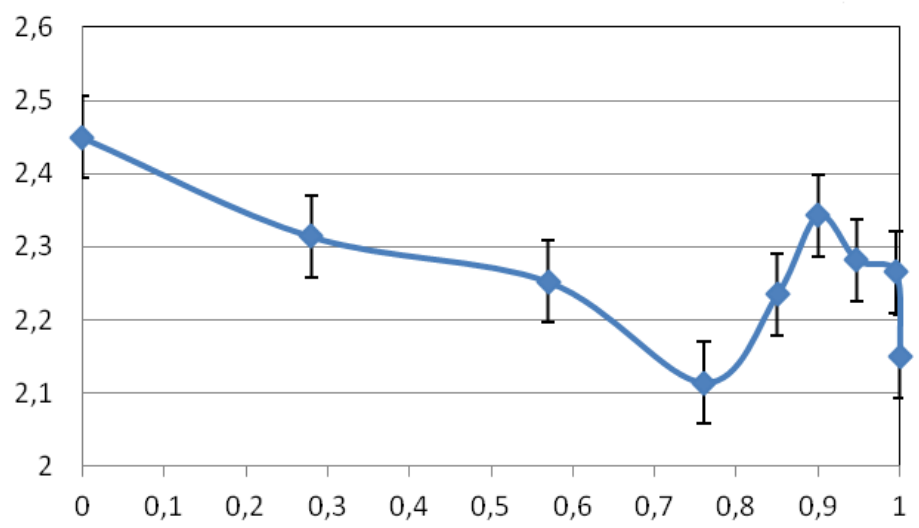

Fig. 13. The change in hidden order (a), fractal dimension (b) and the degree of homogeneity (c) from the level of accumulated fatigue damage [12]

The multifractal parameters characterizing the distribution of hardness over the surface of a cylindrical shell turned out to be very sensitive to the accumulation of fatigue damage and can be used as an additional parameter in the determination of the limiting state of a structural material.

\section{CONCLUSION}

The studies showed that an integrated approach to the determination of the limiting state of a structural material and structure makes it possible to eliminate the ambiguity in the interpretation of measurement results. The use of measurements of surface energy, electromagnetic characteristics, electrical signal response and hardness in the process of destruction accumulation makes it possible not only to fix the onset of the limit state, but also to predict the localization of the place of destruction. It was shown that such multifractal characteristics of the distribution of hardness over the surface of an object, such as the fractal dimension, hidden order, and the degree of homogeneity, turned out to be very sensitive to the accumulation of damages from cyclic loads. The monitoring of damage accumulation in constant mode is proposed to be conducted on the most informative parameter the response of electrical signal.

\section{Acknowledgment}

The present research is conducted in Ufa State Petroleum Technological University as a part of developing of initiative fundamental scientific project according to the state order of 
higher education for 2017-2019 (№ 9.7294.2017 / CU of 31.01.2017)

\section{References}

[1] Yu.V. Lisin, D.A. Neganov, A.A. Sergaev, "Determination of permissible operating pressures for long-running main pipelines based on the results of in-line diagnostics", 2016, p.30-37.

[2] A.K. Gaidukevich, "Improving the quality of acoustic emission control of pressure vessels in oil refining and petrochemistry: dissertation", Ufa, 2001, p. 89

[3] J. Baran, M. Rosen, «Effect of grain size on the acoustic emission generated during plastic deformation in cooper, material science and engineering», [Vliyanie razmera zerna na akusticheskuyu ehmissiyu, voznikayushchuyu pri plasticheskoj deformacii v medi, materialovedenii i tekhnike], 1981, p. 243-246.

[4] ANL/EVS/TM/08-5 (2007), Natural gas pipeline technology overview, p. 55

[5] N.W. Ashcroft, N.D. Mermin, H.R. Winston, "Solid State Physics", [Fizika tverdogo tela] New York, 1976, p. 826.

[6] H. Hermann, "Synergetics An Introduction" [Vvedenie v sinergetiku], 1983, p. 390.

[7] I. Prigogine, I. Stengers, "Order out of chaos: Man's new dialogue with nature Heinemann" [Poryadok iz haosa: novyj dialog cheloveka s prirodoj Hajnemann], 1984, London.

[8] Y.S. Kovshova, I.R. Kuzeev, E.A. Naumkin, N.A. Makhutov, M.M Gadenin, «The influence of quasi-static loading regimes on the strength of vessels operating under pressure» [Vliyanie rezhimov kvazistichesko] zagruzki na prochnost' sudov, rabotayushchih pod davleniem], Inorganic Materials, vol. 51(15), 2015, pp. 1502-1507

[9] J.P. Wolfe, "Physics Today" [Fizika Segodnya], 1982, p. 46

[10] J.G. Dash, "Physics Today" [Fizika segodnya], 1985, p. 26

[11] I.R. Kuzeyev, E.A. Naumkin, R.R. Kudashev, A.A. Ryabov, B.B Konovalov, «Change of mechanical behavior of elastic tubing material in periodic loading conditions» [Izmeneniya mekhanicheskih harakteristik materiala gibkih nasosno-kompressornyh trub v usloviyah ciklicheskogo nagruzheniya], SOCAR Proceedings (2), 2015, pp. 47-53

[12] A.V. Samigullin, E.A. Naumkin, I.R. Kuzeev, A.N. Tepzaev, "Multifractal parametrization of the results of the hardness of the material of the shell structure subjected to cyclic loading", Electronic scientific journal "Oil and Gas Business", 2015, p. 323-338.

[13] A.G. Chirkova, L.G. Avdeeva, A.S. Simarchuk, "Fractal analysis of the evolution of the adaptation of the structure of steel $20 \mathrm{X} 23 \mathrm{H} 18$ to the operating conditions in the pyrolysis furnaces of hydrocarbons", St. Petersburg: Nedra, 2004, p. 88.

[14] A.G. Kolmakov, G.V. Vstovsky, «Multifractal Analysis of Metallic Surface Structure Changes», 1999, p. 705-710.

[15] H. Chen, «Toptig robot welding technology and welding join performance research of the aircraft engine bladeshen», Shanghai Jiaotong Daxue Xuebao: Journal of Shanghai Jiaotong University 50, 2016, pp. 114-116

[16] A.A. Shanyavsky, "Modeling fatigue damage to metals", Synergetic in Aviation, Ufa: Monograph LLC, 2007, p. 500.

[17] Ch.-H. Hsueh, S. Schmauder, C.-S. Chen, K.K. Chawla, N. Chawla, W. Chen, Y. Kagawa, "Handbook of Mechanics of Materials" [Spravochnik po mekhanike materialov], Springer Nature Singapore Pte Ltd, 2018, p. 2426 . 